\title{
The Malay version of the Early Childhood Oral Health Impact Scale (Malay-ECOHIS) - assessing validity and reliability
}

\author{
Azlina N. Hashim, Zamros Y. M. Yusof ${ }^{*}$ and Rashidah Esa
}

\begin{abstract}
Background: The Early Childhood Oral Health Impact Scale (ECOHIS) is used to assess oral impacts on the quality of life of preschool aged children and their families. The objective of this study was to perform a cross-cultural adaptation of the ECOHIS into Malay and assess its psychometric properties.

Methods: The cross-Cultural adaptation of ECOHIS into Malay comprised of translating the ECOHIS into the Malay language (Malay-ECOHIS) by experts followed by face validation of the Malay-ECOHIS by a group of mothers. The Malay-ECOHIS was back translated into English and this was compared with the original ECOHIS. Minor changes were made to the Malay-ECOHIS before it was finalised. The Malay-ECOHIS' psychometric properties were assessed in terms of construct, convergent and discriminant validity as well as internal and test-retest reliability based on two separate studies involving 127 parents of 4-6 year old preschool children followed by oral examinations of 860 preschool children from 25 kindergartens from two districts in Selangor state, Malaysia. Non-parametric statistics were used to assess the relationships between the Malay-ECOHIS and the subjective and clinical outcome measures.
\end{abstract}

Results: The Cronbach's alpha was 0.83 and the weighted Kappa was 0.95 (intraclass correlation =0.94). The Malay-ECOHIS demonstrated significant associations with different subjective and normative measures, i.e. levels of oral health satisfaction, perceived oral health status, perceived oral health need, toothache experience, pattern of dental attendance, and caries status of preschool children. These significant associations supported its construct, convergent and discriminant validity as well as internal and test-retest reliability.

Conclusion: This study showed that the Malay-ECOHIS is a valid and reliable instrument to assess the negative impacts of oral disorders/conditions on the quality of life of 4-6 year old preschool children and their families in Malaysia.

Keywords: Malaysia, Oral health, Preschool children, Quality of life

\section{Background}

Oral health related quality of life (OHRQoL) indicators have been developed to assess the impact of oral conditions on daily life [1]. In young children, assessing oral impacts on daily performances is important because poor oral health can affect not only their future dentition, but also their growth, weight, social life, self-esteem and school performance $[2,3]$. In addition, as they depend a lot on their parents, dental problems in young

\footnotetext{
* Correspondence: zamros@um.edu.my

Department of Community Oral Health and Clinical Prevention, Faculty of Dentistry, University of Malaya, 50603, Kuala Lumpur, Malaysia
}

children often have consequences on their parents, caregivers, and siblings who live with the child $[4,5]$. In severe cases where the child's oral impacts persist for years, their effect on the child may last until adulthood [6].

In young children, assessing oral impacts on daily performances requires a special approach. This is because young children often have cognitive limitations in recalling past events. Their memories may be unreliable and they are unable to express themselves fully. Thus, parent's input to validate such findings is essential $[3,7]$. In addition, children's oral health problems do not exist in 
isolation but often affect other family members in real life situations [5]. Thus, when measuring young children's OHRQoL, parental input on children's oral health problems and their impacts on the child's wellbeing, their siblings and the family dynamics is important [8].

Taking into account the various limitations in assessing OHRQoL in young children, the Early Childhood Oral Health Impact Scale (ECOHIS) was developed to overcome such limitations [9]. The primary objective of ECOHIS is to measure young children's oral impacts on daily life including those of family members. The scale has been validated on 3-5 year old children and their families in English in the USA. It has been translated into several versions, i.e. French, Chinese, Farsi, Turkish, Spanish, Lithuanian, Bosnia-Herzegovina and Brazilian [10-17]. Overall, the ECOHIS showed high degree of success in the assessment of oral impacts in young children with medical conditions $[18,19]$, traumatic dental injuries and malocclusions [20] and those with early childhood caries [21]. It has also been used to assess young children's OHRQoL following treatment under general anaesthesia [22]. In the community, the use of the scale would allow for the development of effective oral health programmes and services because it permits assessment of young children's perceived needs, levels of care required and treatment strategy effectiveness [8, 23, 24].

The aim of the present study was to perform a crosscultural adaptation of the English ECOHIS into Malay followed by psychometric analysis of the Malay-ECOHIS.

\section{Methods}

The development of the Malay-ECOHIS involved two phases. The first phase involved the cultural adaptation of the English ECOHIS into Malay [25]. The second phase involved psychometric validations of the newly developed Malay-ECOHIS [26, 27].

In the cross-cultural adaptation phase, the English ECOHIS was first translated into the Malay language by a team of independent translators consisted of a psychologist, a peadodontist, dental public health specialists and experts in quality of life assessment. The experts were also proficient in both Malay and English languages. Next, the experts met together to analyse the content and wordings of the translations. The objective was to ensure that conceptual and item equivalence between the original ECOHIS and its Malay versions were maintained throughout the process [28]. Conceptual equivalence is achieved when answers to the same questions reflect the same concept in the original ECOHIS and its Malay version respectively, and also the concepts are meaningful in both cultures and languages concerned. Item equivalence is achieved when the meaning of the individual item in both sets of questionnaires is contextually similar. Following the meeting, the experts agreed on one consensus translation derived from the translations. The consensus translation was called the draft Malay-ECOHIS.

Next, the draft-Malay ECOHIS was tested for face validity on a non-random sample of 20 mothers of 4-6 year old children in a classroom setting at one of the kindergartens supervised by one of the authors (RE) [26]. The time taken to answer the questionnaire was noted. Afterwards, the author (RE) undertook a detailed discussion with the mothers on their understanding of the purpose, instructions, content, wordings, answering options, and general layout of the questionnaire. Based on the mothers' feedback, a minor adjustment was made to the draft Malay-ECOHIS. The mode of questionnaire administration was self-administered.

Next, the draft Malay-ECOHIS was back translated into English by a language expert from the Department of Languages, University of Malaya who was proficient in both English and Malay languages. Then, the experts reconvened to compare the back translation with the original ECOHIS. After minor modifications, the experts agreed on the back translation of the Malay-ECOHIS. Small changes to the draft Malay-ECOHIS were made accordingly before it was finalised.

The assessment of the Malay-ECOHIS psychometric properties involved 2 studies. In study 1, the MalayECOHIS was distributed by one of the authors (NAH) to a convenient sample of 127 parents of 4-6 year old children from two public and one private kindergarten in Kelana Jaya district in the Selangor state. To assess the test-retest reliability, the scale was redistributed to $20 \%$ of the sample after 10 days [9]. In study 2, in order to assess the relationship between the Malay-ECOHIS and clinical outcomes, the scale was distributed by RE and ZY to 860 parents of 4-6 year old preschool children from 25 kindergartens from 2 districts in Selangor state. Oral examinations were undertaken on the children.

\section{The questionnaire}

The Malay-ECOHIS comprised 13 items divided into two main parts, i.e. the child impacts section and the family impacts section. The number of items and sections in the Malay-ECOHIS were similar to the original ECOHIS [9]. In the Malay-ECOHIS, the child impacts section contained four domains, i.e. child symptom (1 item), child function (4 items), child psychology (2 items) and child self-image and social interaction ( 2 items). The family impacts section contained two domains, i.e. parental distress ( 2 items) and family function ( 2 items).

The questionnaire has 5 response options: $0=$ never, $1=$ hardly ever, $2=$ occasionally, $3=$ often, $4=$ very often, and $5=$ don't know. The different score ranges for each domain were as follows: child symptom, range $0-4$; child function, range $0-16$; child psychology, range $0-8$; child 
self-image/social interaction, range $0-8$; parental distress, range $0-8$ and family function, range $0-8$. Total score was calculated by simply summing up the response codes of the 13 items. Thus, the overall score ranged between 0 and $52(0-36$ for the child section and $0-16$ for the family section). In our study, we dealt with 'don't know' (DK) responses by following the method of data scoring proposed in the original version, where DK responses were recoded as missing values [9]. In cases with up to 2 missing responses in the child section or 1 missing response in the parent section, we ascribed the score for the missing value as the average of the rest of the items for that section [9]. Subsequently, we only excluded cases with more than 2 missing responses in the child section or more than 1 in the family section. When answering the Malay-ECOHIS, parents were asked to consider the lifetime experience of the child with regard to oral problems and related impacts. Higher scores indicate greater oral impacts and poorer OHRQoL and vice versa.

In our study, the inclusion criteria were mothers of children aged between 4 and 6 years with no chronic medical conditions, no long-term medication, no physical or learning disabilities, and accompanied by a Malay-speaking parent who lived with the child most of the time.

\section{Ethics, consent and permissions}

Ethical approval for the study was granted by the Medical Ethics Committee, Faculty of Dentistry, University of Malaya [Reference: DF CO1403/0042(P)]. Permission to conduct the study was obtained from the State Education Department, State Oral Health Division (Selangor), kindergarten teachers and parents of the children.

Information about the study was given to the parents to read. A written consent from the parent was obtained before they answered the questionnaire.

\section{Data analysis}

In this study, psychometric properties of the MalayECOHIS were analysed by assessing its internal consistency and test-retest reliability as well as construct, convergent and discriminant validity.

For internal consistency reliability, Cronbach's alpha coefficient, inter-item correlation and corrected item-total correlation were used to assess the degree of homogeneity of the child and family impacts sections. Cronbach's alpha values $\geq 0.70$ were considered acceptable for comparison between groups [29]. The test-retest reliability test was carried out to ensure the Malay-ECOHIS would yield consistent scores when administered at two different times [30]. This was determined by the weighted kappa value for categories of Malay-ECOHIS scores and Intraclass Correlation Coefficient (ICC) in a one-way random effect parallel model for the child and family impacts sections. The $95 \%$ confidence interval was estimated. The degree of test-retest reliability was assessed based on the ICC values, i.e. $\leq 0.40=$ weak, 0.41 to $0.60=$ moderate, 0.61 to $0.80=$ good, and 0.81 to $1.00=$ excellent [31]. Arbitrary guidelines characterized kappa value over 0.75 as excellent, 0.40 to 0.75 as fair to good, and below 0.40 as poor [32].

The ability of the Malay-ECOHIS to assess pre-school children's OHRQoL was assessed by examining the association between Malay ECOHIS scores and a number of subjective variables designed to indicate, both objectively and subjectively, the levels of oral health status and quality of life of the study population.

Convergent validity of the Malay-ECOHIS was tested on its ability to measure what it intended to measure [30]. In this study, the Malay-ECOHIS was intended to measure child's oral impacts which also mirrored levels of child's oral health status. Consequently, the convergent validity was tested by comparing its relationship with a suitable global oral health rating item on perceived oral health status of the child, i.e. "How do you describe your child's oral health status?" The underlying hypothesis was that parents who rated their child's oral health status as poor would score highly on the MalayECOHIS.

Construct validity of the Malay-ECOHIS was assessed by comparing its relationships with other measures that assess related constructs, i.e. perceived satisfaction on child's oral health, perceived child's treatment needs, and presence of toothache. The items used were (1) "How satisfied are you with your child's teeth/mouth?" (2) "In your opinion, would your child require any dental treatment?" and (3) "How often has your child had pain in their teeth, mouth or jaws?" The hypothesis related to the tests was that preschool children whose oral health was rated as less satisfactory and needed dental treatment and those with pain in their teeth and mouth would experience lower levels of OHRQoL and higher Malay-ECOHIS scores. The impacts of child's oral health on his/her daily life were also closely related to the impacts on family members $[8,9]$.

Discriminant validity of the Malay-ECOHIS was tested by comparing its relationship with the child's dental visits due to dental problems and the child's caries status. The hypothesis behind this was that mothers who often brought their child to the dentist for treatment were more likely to report that their child experienced dental problems. Likewise, children with caries would have significantly higher oral impacts than children with no caries.

In this study, the Malay-ECOHIS scores were skewed. Therefore, non-parametric statistics, i.e. Kruskal-Wallis and Mann Whitney were used to assess relationships 
between the Malay-ECOHIS and subjective/objective measures [30]. Data distribution was described in terms of mean and median. The SPSS statistical package version 17 was used for data analysis [33]. The level of statistical significance was set at $p<0.05$.

\section{Results}

The 127 participating parents comprised parents of 64 boys $(50.4 \%)$ and 63 girls (49.6 \%). The children's mean age was 5 years old $(\mathrm{SD}=0.6)$. The sample was predominantly Malay ( $n=124,97.6 \%), 2$ Indian (1.6\%), and 1 Chinese $(0.8 \%)$ with varying socioeconomic background (Table 1).

More children attended private $(n=67,52.8 \%)$ than public kindergartens. More than one-third of the children were the eldest in the family $(n=36,28.3 \%)$ and the mean number of siblings was $3.1(\mathrm{SD}=1.4)$. The majority of parents were mothers $(62.2 \%)$. More than onethird of mothers (35.4\%) and $30.7 \%$ of fathers had education up to university level. About one-fifth of parents had monthly income of RM1000-2999 (low income level), less than half (45.7 \%) had monthly income of RM 3000-4999 (moderate income level) and $33.0 \%$ had monthly income of $>$ RM5000 (high income level).

Table 2 shows the parents' responses to the MalayECOHIS with regard to their child's oral conditions. In the child impacts section, less than half of children were reported to have suffered from "pain in the teeth, mouth or jaws" (40.9\%). The most frequently reported oral impact was "difficulty in eating some foods" (27.6 \%), followed by "difficulty in drinking hot and cold beverages" (18.1\%), "became irritable or frustrated" (17.3\%), and "had trouble sleeping" (15.7\%).

In the family impacts section, the most frequently reported impacts were "parents or family members feeling guilty" (37.8 \%) and "felt upset" (32.3\%) as the results of the child's oral conditions. In the child impacts section, 2 parents chose "Don't Know" on the items related to "missed preschool, day care or school" and "their child had been irritable or frustrated". In the family impacts section, 2 parents answered "Don't Know" on the items "felt guilty" and "financial impact on family". In this study, the Malay-ECOHIS scores ranged from 0 to 17 in the child impacts section (mean $=2.4, \mathrm{SD}=3.6)$, and $0-7$ in the family impacts section (mean $=1.2, \mathrm{SD}=1.8$ ).

Table 3 shows the inter-item correlation coefficients of the 13-item scores of the Malay-ECOHIS. The interitem correlation coefficients ranged from 0.005 to 0.807 . The weakest correlation was between items "irritation" and "financial impact" with coefficient value of 0.005 while the strongest correlation was between items "smiling" and "talking" with coefficient value of 0.807 . Six correlations involving the item "financial" had negative coefficient values.
Table 1 Demographic characteristics of the sample of preschool aged children and their parents $(N=127)$

\begin{tabular}{|c|c|c|}
\hline \multirow[t]{2}{*}{ Demographic characteristic } & \multicolumn{2}{|c|}{ Frequency } \\
\hline & $\mathrm{n}$ & $\%$ \\
\hline \multicolumn{3}{|l|}{ Child's characteristics } \\
\hline \multicolumn{3}{|l|}{ Age (years) } \\
\hline 6 & 61 & 48.0 \\
\hline 5 & 55 & 43.3 \\
\hline 4 & 11 & 8.7 \\
\hline \multicolumn{3}{|l|}{ Gender } \\
\hline Boys & 64 & 50.4 \\
\hline Girls & 63 & 49.6 \\
\hline \multicolumn{3}{|l|}{ Race } \\
\hline Malay & 124 & 97.6 \\
\hline Chinese & 1 & 0.8 \\
\hline Indian & 2 & 1.6 \\
\hline \multicolumn{3}{|l|}{ Kindergarten } \\
\hline Tadika KEMAS Nurul Jamruk (public) & 45 & 35.4 \\
\hline Tadika KEMAS Nur Ar-Rahim (public) & 15 & 11.8 \\
\hline Tadika Cahaya Taqwa (private) & 67 & 52.8 \\
\hline \multicolumn{3}{|l|}{ Child's position in the family } \\
\hline Eldest child & 36 & 28.3 \\
\hline Second child & 35 & 27.6 \\
\hline Third child & 24 & 18.9 \\
\hline Fourth child & 21 & 16.5 \\
\hline Fifth child & 7 & 5.5 \\
\hline Sixth child & 3 & 2.4 \\
\hline Other & 1 & 0.8 \\
\hline
\end{tabular}

Parent's characteristics

Relationship to child

Mother

62.2

Father

Level of education (mother)

Secondary school

37.8

Diploma or equivalent

26.8

University

35.4

Level of education (father)

Secondary school

Diploma or equivalent

41.7

University

27.6

Monthly family income $e^{a}$

RM 1000 - RM 2999 (low)

30.7

RM 3000 - RM 4999 (moderate)

21.3

$>$ RM 5000 (high)

45.7

33.0

${ }^{\mathrm{a}} \mathrm{RM}=$ Ringgit Malaysia (RM1 = USD $0.27=$ GBP 0.18) 
Table 2 Malay-ECOHIS responses of parents $(n=127)$

\begin{tabular}{|c|c|c|c|c|c|c|c|c|c|c|c|c|c|}
\hline \multirow[t]{2}{*}{ Impacts } & \multicolumn{2}{|c|}{ Never } & \multicolumn{2}{|c|}{ Hardly ever } & \multicolumn{2}{|c|}{ Occasionally } & \multicolumn{2}{|c|}{ Often } & \multicolumn{2}{|c|}{ Very often } & \multicolumn{2}{|c|}{ Don't know } & \multirow[t]{2}{*}{ Mean $(S D$} \\
\hline & $\mathrm{n}$ & $\%$ & $\mathrm{n}$ & $\%$ & $\mathrm{n}$ & $\%$ & $\mathrm{n}$ & $\%$ & $\mathrm{n}$ & $\%$ & $n$ & $\%$ & \\
\hline \multicolumn{14}{|l|}{ Child impacts } \\
\hline $\begin{array}{l}\text { How often has your child had pain in the teeth, } \\
\text { mouth or jaws }\end{array}$ & 75 & 59.1 & 9 & 7.1 & 41 & 32.3 & 1 & 0.8 & 0 & 0 & 1 & 0.8 & $0.75(0.95)$ \\
\hline \multicolumn{14}{|l|}{$\begin{array}{l}\text { How often has your child .......... because } \\
\text { of dental problems or dental treatments? }\end{array}$} \\
\hline had difficulty drinking hot or cold beverages & 104 & 81.9 & 7 & 5.5 & 15 & 11.8 & 0 & 0 & 0 & 0 & 1 & 0.8 & $0.29(0.67)$ \\
\hline had difficulty eating some foods & 92 & 72.4 & 13 & 10.2 & 20 & 15.7 & 2 & 1.6 & 0 & 0 & 0 & 0 & $0.46(0.81)$ \\
\hline had difficulty pronouncing any words & 114 & 89.8 & 5 & 3.9 & 6 & 4.7 & 0 & 0 & 1 & 0.8 & 1 & 0.8 & $0.17(0.58)$ \\
\hline missed preschool, day care or school & 124 & 97.6 & 1 & 0.8 & 0 & 0 & 0 & 0 & 0 & 0 & 2 & 1.6 & $0.01(0.09)$ \\
\hline had trouble sleeping & 107 & 84.3 & 8 & 6.3 & 12 & 9.4 & 0 & 0 & 0 & 0 & 0 & 0 & $0.25(0.62)$ \\
\hline been irritable or frustrated & 105 & 82.7 & 10 & 7.9 & 10 & 7.9 & 0 & 0 & 0 & 0 & 2 & 1.6 & $0.24(0.59)$ \\
\hline avoided smiling or laughing & 114 & 89.8 & 5 & 3.9 & 8 & 6.3 & 0 & 0 & 0 & 0 & 0 & 0 & $0.17(0.52)$ \\
\hline avoided talking & 118 & 92.9 & 4 & 3.1 & 4 & 3.1 & 0 & 0 & 0 & 0 & 1 & 0.8 & $0.10(0.39)$ \\
\hline \multicolumn{14}{|l|}{ Family impacts } \\
\hline \multicolumn{14}{|l|}{$\begin{array}{l}\text { How often have you or another family } \\
\text { member ........... because of your child's } \\
\text { dental problems or treatment? }\end{array}$} \\
\hline been upset & 86 & 67.7 & 25 & 19.7 & 12 & 9.4 & 3 & 2.4 & 0 & 0 & 1 & 0.8 & $0.46(0.77)$ \\
\hline felt guilty & 79 & 62.2 & 26 & 20.5 & 15 & 11.8 & 5 & 3.9 & 0 & 0 & 2 & 1.6 & $0.57(0.86)$ \\
\hline taken time off from work & 112 & 88.2 & 11 & 8.7 & 3 & 2.4 & 0 & 0 & 0 & 0 & 1 & 0.8 & $0.13(0.41)$ \\
\hline $\begin{array}{l}\text { How often has your child had dental problems } \\
\text { or dental } \\
\text { treatments that had a financial impact on your family? }\end{array}$ & 120 & 94.5 & 2 & 1.6 & 3 & 2.4 & 0 & 0 & 0 & 0 & 2 & 1.6 & $0.06(0.33)$ \\
\hline
\end{tabular}

Table 4 shows the corrected item-total correlation of the 13 items of the Malay-ECOHIS. The corrected itemtotal correlation values were all positive ranging from 0.04 to 0.68 . Of the 13 items, 11 had corrected itemtotal correlation values above 0.3. The lowest value was related to "financial impact" (0.04) while the highest value was related to "eating" (0.68) and "irritation" (0.68). The Cronbach's alpha coefficient was 0.83 and the coefficient only increased by 0.01 if the item on financial impact was deleted. For the test-retest reliability, the weighted kappa value was 0.95 and the intraclass correlation coefficient (ICC) was 0.94 .

Table 3 The Malay-ECOHIS reliability analysis: inter-item correlation coefficients of the 13 items

\begin{tabular}{|c|c|c|c|c|c|c|c|c|c|c|c|c|c|}
\hline & Pain & Drinking & Eating & Pronouncing & Absence & Sleeping & Irritation & Smiling & Talking & Upset & Guilty & Work & Financial \\
\hline Pain & 1.000 & & & & & & & & & & & & \\
\hline Drinking & .489 & 1.000 & & & & & & & & & & & \\
\hline Eating & .491 & .641 & 1.000 & & & & & & & & & & \\
\hline Pronouncing & .350 & .532 & .406 & 1.000 & & & & & & & & & \\
\hline Absence & .121 & .236 & .180 & .129 & 1.000 & & & & & & & & \\
\hline Sleeping & .455 & .467 & .332 & .185 & .115 & 1.000 & & & & & & & \\
\hline Irritation & .415 & .478 & .615 & .249 & -.038 & .533 & 1.000 & & & & & & \\
\hline Smiling & .219 & .292 & .546 & .122 & -.030 & .347 & .622 & 1.000 & & & & & \\
\hline Talking & .110 & .301 & .416 & .211 & -.023 & .385 & .521 & .807 & 1.000 & & & & \\
\hline Upset & .270 & .200 & .386 & .363 & .066 & .124 & .311 & .271 & .126 & 1.000 & & & \\
\hline Guilty & .373 & .280 & .323 & .330 & .049 & .263 & .392 & .113 & .084 & .763 & 1.000 & & \\
\hline Work & .196 & .304 & .138 & .137 & .190 & .195 & .176 & .083 & .167 & .219 & .328 & 1.000 & \\
\hline Financial & -.001 & -.013 & -.049 & -.060 & -.018 & -.039 & .005 & .031 & .075 & .077 & .106 & .172 & 1.000 \\
\hline
\end{tabular}


Table 4 Reliability analysis: corrected item-total correlation of the 13 items of the Malay-ECOHIS, Cronbach's alpha coefficient, Intraclass Correlation Coefficient (ICC) and kappa coefficient

\begin{tabular}{lcc}
\hline & $\begin{array}{c}\text { Corrected item-total } \\
\text { correlation }\end{array}$ & $\begin{array}{c}\text { Cronbach's alpha } \\
\text { if item deleted }\end{array}$ \\
\hline Pain & .55 & .81 \\
Drinking & .64 & .80 \\
Eating & .68 & .80 \\
Pronouncing & .47 & .82 \\
Absence & .15 & .83 \\
Sleeping & .50 & .81 \\
Irritation & .68 & .80 \\
Smiling & .49 & .82 \\
Talking & .45 & .82 \\
Upset & .51 & .81 \\
Guilty & .54 & .81 \\
Work & .32 & .83 \\
Financial & .04 & .84 \\
Cronbach's alpha coefficient & 0.83 & \\
Intraclass Correlation & 0.94 & \\
Coefficient (ICC) & & \\
Weighted kappa value & 0.95 & \\
\hline
\end{tabular}

Table 5 shows the results of the construct, convergent and discriminant validity tests of the Malay-ECOHIS. There was a trend of increasing Malay-ECOHIS scores from parents who were "very satisfied" to those who were "very unsatisfied" with their child's teeth/mouth $(p<0.001)$. Similar trend was observed on parents who perceived their child's oral health status as "excellent" to those who perceived their child's oral health status as "poor" $(p<0.001)$.

Parents who perceived their child as needing dental treatment had significantly higher Malay-ECOHIS scores than those who perceived their child as not needing dental treatment. Those who were unsure had lowest Malay-ECOHIS scores compared with the other two groups of parents. The trend was statistically significantly $(p<0.001)$.

Parents who reported their child had toothache "very often" had significantly higher Malay-ECOHIS scores than those who reported their child had "occasional" toothache; and those who reported their child had no toothache at all $(p<0.001)$.

Children who never went to see the dentist because of dental problems had significantly lower Malay-ECOHIS scores than children who went to the dentist occasionally; and children who went to the dentist regularly because of dental problems $(p<0.001)$.

Table 6 shows further evidence on discriminant validity of the Malay-ECOHIS. For each of the child impacts section, family impacts section, and the overall score, the mean Malay-ECOHIS scores were significantly higher in children with caries than children without caries. The effect size for each section was small with caries-free children having better OHRQoL than children with caries. Also, there is some suggestion of floor effects for the child impacts section, parent impacts section and the overall scale which had $21 \%$ or more scoring 0 on each section respectively.

\section{Discussion}

In this study, the original English ECOHIS was crossculturally adapted into Malay by following a standard published procedure $[25,26]$. Overall, based on the validity and reliability tests analyses, the 13 -item MalayECOHIS has been proven to be valid and reliable for use by parents of 4-6 year old pre-school children in Malaysia to assess children's oral impacts on quality of life and their family. The questionnaire's mode of administration was self-administered.

In the content validation analysis, the experts had unanimously agreed that the forward and back translations of the Malay-ECOHIS satisfied the content and item equivalence requirements between the English ECOHIS and its Malay version [28]. The back translation was found to be closely similar to the original ECOHIS with a slight adjustment made to the Malay version.

In the face validation test analysis, the utility of the Malay-ECOHIS as a self-administered questionnaire had been verified and agreed upon by a group of mothers through discussion after they had answered the questionnaire. Their input was taken into consideration in the final draft of the Malay-ECOHIS. In this pre-test, only mothers were involved as most mothers were present during the pre-test and volunteered for the study. None of the fathers whom we approached were willing to volunteer. In the Asian culture, mothers play the dominant role in raising the child and are more willing to participate in activities concerning the child's welfare. Also, the majority of mothers are home makers and thus have more time with their child. As such, their input and understanding of the scale was important. As the maternal influence in the child upbringing is foremost, we felt the absence of fathers in the pre-test would not compromise the validity of the scale in a significant way.

Through content and face validation test analyses, the experts verified that the 13-item Malay-ECOHIS was contextually similar to the original ECOHIS. The mothers commented that the scale was relatively short, easy to understand, relevant, and suitable to assess young children's oral impacts in the Malaysian setting.

In terms of the layout, the Malay-ECOHIS followed the original ECOHIS in terms of design and presentation. It was interesting to note that the 3 most common 
Table 5 Construct, convergent and discriminant validity tests for the Malay-ECOHIS - associations between Malay-ECOHIS and subjective outcome variables $(n=123)$

\begin{tabular}{|c|c|c|c|c|c|}
\hline Variables & $n$ & Mean & $(S D)$ & ECOHIS score (Quartiles) & $\mathrm{P}^{*}$ \\
\hline \multicolumn{6}{|c|}{ Perceived satisfaction on child's oral health } \\
\hline Very satisfied & 8 & 0.88 & $(2.47)$ & $(0.0,0.0,0.0)$ & \multirow[t]{5}{*}{$<0.00$} \\
\hline Satisfied & 56 & 2.21 & $(3.72)$ & $(0.0,0.0,3.8)$ & \\
\hline Moderate & 37 & 4.68 & $(4.47)$ & $(0.0,4.0,8.0)$ & \\
\hline Not satisfied & 18 & 5.22 & $(4.75)$ & $(1.8,4.0,8.3)$ & \\
\hline Very unsatisfied & 4 & 11.25 & $(7.41)$ & $(5.3,9.5,19.0)$ & \\
\hline \multicolumn{6}{|l|}{ Perceived child's oral health status } \\
\hline Excellent & 7 & 1.00 & $(2.65)$ & $(0.0,0.0,0.0)$ & \multirow[t]{5}{*}{$<0.001$} \\
\hline Very good & 19 & 1.42 & $(3.82)$ & $(0.0,0.0,0.0)$ & \\
\hline Good & 50 & 3.16 & $(4.01)$ & $(0.0,1.5,5.0)$ & \\
\hline Moderate & 40 & 4.65 & $(4.59)$ & $(1.0,4.0,7.8)$ & \\
\hline Poor & 7 & 9.29 & $(6.18)$ & $(5.0,6.0,13.0)$ & \\
\hline \multicolumn{6}{|l|}{ Perceived child's oral health need } \\
\hline Yes & 94 & 4.57 & $(4.80)$ & $(0.0,4.0,7.0)$ & \multirow[t]{3}{*}{$<0.001$} \\
\hline No & 21 & 0.48 & $(1.44)$ & $(0.0,0.0,0.0)$ & \\
\hline Don't know & 8 & 0.38 & $(0.74)$ & $(0.0,0.0,0.75)$ & \\
\hline \multicolumn{6}{|l|}{ Child's experience of toothache } \\
\hline Very often & 1 & 19.0 & $(0.00)$ & $(19.0,19.0,19.0)$ & \multirow[t]{3}{*}{$<0.001$} \\
\hline Occasionally & 48 & 6.50 & $(4.68)$ & $(3.0,5.0,10.0)$ & \\
\hline Never & 74 & 1.51 & $(2.81)$ & $(0.0,0.0,3.0)$ & \\
\hline \multicolumn{6}{|c|}{ Dental visit due to dentally related problems } \\
\hline Never & 55 & 1.96 & $(3.72)$ & $(0.0,0.0,3.0)$ & \multirow[t]{3}{*}{$<0.001$} \\
\hline Occasionally when have problems & 62 & 4.92 & $(4.60)$ & $(1.0,4.0,8.0)$ & \\
\hline Regularly & 6 & 5.00 & (7.18) & $(0.8,2.0,9.3)$ & \\
\hline
\end{tabular}

${ }^{*}$ Kruskal-Wallis non-parametric statistics

impacts reported by parents in the child impacts section were similar to those found in the earlier studies of different cultures and settings $[9,10,17]$. These responses were "pain in the teeth, mouth or jaws", "difficulty in eating some foods" and "child being irritable or frustrated". This indicates that the Malay-ECOHIS is comparable to other ECOHIS versions to detect prevalent oral impacts among preschool children across different cultures and settings.
In the internal consistency reliability test analysis in study 1, almost all of the inter-item correlations of the 13 item scores were positive and coefficients ranged from 0.005 to 0.807 . None of the values were above the coefficient value of 0.9 indicating that no items were deemed redundant. The items were mostly correlated with one another in a positive manner. Only one item, i.e. 'financial impact', had negative inter-item coefficients with six other items in the child impacts section.

Table 6 Discriminant validity of Malay ECOHIS through comparison of mean Malay-ECOHIS scores and respective sub-scales by caries status

\begin{tabular}{|c|c|c|c|c|c|c|}
\hline \multirow[t]{2}{*}{ M-ECOHIS } & Caries & Caries-free & $p$-value* & Cohen's $d^{a}$ & \multirow{2}{*}{$\begin{array}{l}\text { \% Floor } \\
\text { (0 score) }\end{array}$} & \multirow{2}{*}{$\begin{array}{l}\text { \% Ceiling } \\
\text { (max score) }\end{array}$} \\
\hline & Mean (SD) & Mean (SD) & & & & \\
\hline Child impact section & $13.1(4.00)$ & $12.17(4.78)$ & $<0.001$ & 0.21 & 27.0 & 0.1 \\
\hline Family impact section & $5.35(2.01)$ & $4.85(2.18)$ & $<0.001$ & 0.24 & 58.4 & 0.2 \\
\hline Overall score & $18.44(5.39)$ & $17.00(6.46)$ & $<0.001$ & 0.24 & 21.6 & 0 \\
\hline
\end{tabular}

SD standard deviation

*Mann-Whitney statistics

${ }^{\mathrm{a}} 0.21<\mathrm{d}<0.24=$ small effect size respectively 
However, the negative values were extremely small. Further psychometric analysis showed no unfavourable effect of the financial impact item on the scale's overall performance. Thus, it was decided to keep the financial impact item in the scale as it was deemed relevant to its overall construct. The corrected item-total correlations were all positive and 11 of the 13 correlations were above 0.2 indicating that most of the 13 items correlated well with the total score and the scale overall [30]. Furthermore, the Cronbach's alpha value was 0.83 indicating that the scale has good internal consistency, higher than the recommended value of 0.70 [34]. The Cronbach's alpha value did not increase significantly if the financial impact item was deleted. Also, the value was lower than 0.95 indicating that no item was deemed redundant nor overlapped with another in the construct. Other studies on ECOHIS validation also reported Cronbach's alpha values $[10-12,17]$.

In the test-retest analysis, the weighted Kappa score was 0.95 and the intraclass correlation coefficient (ICC) value for the total score was 0.94 indicating that the Malay-ECOHIS has excellent levels of agreement. In effect, it shows that the scale has excellent test-retest reliability where it is able to yield consistent scores when administered at two different times [35]. The value of ICC was similar with that reported in the Brazilian study [17] but higher than that reported in the original, Farsi, and Chinese versions of the ECOHIS (0.84, 0.82 and 0.64 , respectively) $[9,11,12]$.

In the construct, convergent and discriminant vitality test analyses in study 1 , only responses from 123 parents were included. Responses from 4 parents were omitted because they either had more than 2 missing responses in the child section or more than 1 missing responses in the parent section [9]. Overall, the analyses showed that the Malay-ECOHIS had excellent validity in the 3 tests, respectively. In the convergent validity test, the MalayECOHIS showed significant association with perceived oral health status of the children. This finding was consistent with findings from other studies where parents who perceived their child's oral health status as poor had significantly higher ECOHIS scores $[9,10,12,17]$. This finding also supports suggestions that parents can provide valid reports on preschool children's OHRQoL when these conditions are observable $[3,9]$.

In the construct validity test, the Malay-ECOHIS showed significant associations with children's levels of perceived oral health satisfaction, perceived oral health need, and toothache experience. These findings empirically supported the construct validity of the scale.

In the discriminant validity test analysis, the MalayECOHIS has been shown to be able to discriminate between children who went to see a dentist regularly because of oral problems and children who did not see a dentist because they had no dental problems. In Malaysia, pre-school children receive oral examination once a year by dental nurses. Those with no dental problem would not need further treatment and thus only seen once a year by the dental nurses. Those with dental problems, e.g. toothache or decayed teeth, are referred to a dentist for further treatment. Thus, in our study those who went to see the dentist very often were the ones with dental problems with relatively higher oral impacts. The discriminant validity of the scale was proven clinically in study 2 when children with caries had significantly higher MalayECOHIS scores than those with no caries.

In study 1,14 subjects (11\%) had DK responses in the child or family impacts section or both. This percentage was similar to the French study [10] but slightly higher than that in the original ECOHIS study (7\%) [9]. In our study, we decided to include subjects with DK responses in the analysis following the criteria and method of data analysis recommended in the original study [9]. This method of data analysis was similar to other validation studies on the ECOHIS [10, 13, 17]. Furthermore, our decision to include subjects with DK responses in the analysis was based on comments by Jokovic et al in which DK response option is considered essential when a person is tasked to assess the oral impacts and quality of life of another individual and they should be included in the analysis. According to Jokovic et al, the presence of DK responses in the answers reflects specific features of the occurrence under assessment and mirrors the construct being examined rather than errors by the respondents [36]. As a result, as many as 10 out of 14 subjects with DK responses in their answers were included in the analysis.

The sample size $(n=127)$ in study 1 may be criticised to be a bit small. However, sample size requirement in studies on psychometric analysis depends predominantly on the number of items in the scale. In general, for scale with 20 items or less, a sample size between 100 and 200 subjects was reasonable [37]. According to quality criteria for measurement properties of health status questionnaires, at least 50 subjects were necessary for an appropriate analysis of construct validity, reproducibility, responsiveness, and a minimum of 100 subjects are required to perform internal consistency analysis [38]. Thus, for the Malay-ECOHIS psychometric analysis with 13 items, the sample size of 127 was considered sufficient for the purpose of testing its psychometric properties.

This study has a few limitations. Only 4-6 year old children were included in the main psychometric analysis although the scale was developed for 1-5 year old children [9]. Variation in age group between this study and other similar studies was mainly due to logistic reasons. In Malaysia, 1-3 year old children is difficult to reach as the majority stay at home while only a minority 
attend day care centres. As such, there is no meaningful method to capture this age group except during dental visits or at the maternal and child health clinics. However, the number is small and unpredictable. On the other hand, the 4-6 year old group is readily accessible as they attend preschool centres and kindergartens before they enter primary schools. This age group receives various government funded health programmes on yearly basis including annual dental check-up and oral health promotion activities by dental nurses. The use of the scale in this age group has added value in that it may potentially allow assessment of oral health programmes effectiveness particularly against caries as well as to prioritise care, evaluate treatment outcomes and compare preschool children's oral health over time.

The use of the Malay-ECOHIS was based on parent's perceptions of their child's oral conditions and their impacts on the child and family. Consequently, different parents might have different perceptions of their child's oral health. The period of assessment was also different from child to child based on their age. Some parents were uncertain whether or not to include problems with teething as oral impacts when answering the questionnaire. However, this was explained by the researchers when parents were answering the questionnaire.

\section{Conclusion}

This study has shown that the Malay-ECOHIS is a valid and reliable measure to assess negative impacts of oral conditions on the quality of life of 4-6 year old preschool aged children and their families in Malaysia.

\section{Abbreviations \\ ECOHIS: Early childhood oral health impact scale; OHRQoL: Oral health} related quality of life; ICC: Intraclass correlation coefficient.

\section{Competing interests}

The authors declare that they have no competing interests.

\section{Authors' contributions \\ $\mathrm{NAH}$ contributed in the study design, acquisition of data, analysis and interpretation of data, and drafting the manuscript. ZYMY involved in the design of study 1, data collection for study 2, data analysis and reviewed the manuscript. RE involved in the Malay-ECOHIS linguistic validation, data collec- tion for study 2 and reviewed the manuscript. All authors read and approved the final manuscript.}

\section{Acknowledgements}

This study was funded by the University Malaya Research Grant: UMRG301-14AFR.

Received: 29 March 2015 Accepted: 19 November 2015

Published online: 25 November 2015

\section{References}

1. Slade GD. Measuring oral health and quality of life. Chapel Hill: University of North Carolina; 1997.
2. Sheiham A. Dental caries affects body weight, growth and quality of life in pre-school children. Br Dent J. 2006;201(10):625-6.

3. Filstrup $S L$, Briskie D, Da Fonseca M, Lawrence L, Wandera A, Inglehart M. Early childhood caries and quality of life: child and parent perspectives. Pediatr Dent. 2003;25(5):431-40.

4. Petersen PE. The World Oral Health Report 2003: continuous improvement of oral health in the 21st century - the approach of the WHO Global Oral Health Programme. Community Dent Oral Epidemiol. 2003;31:3-24.

5. Gift HC, Reisine ST, Larach DC. The social impact of dental problems and visits. Am J Public Health. 1992;82(12):1663-8.

6. Feldens $C A$, Giugliani ERJ, Duncan BB, Drachler ML, Vítolo MR. Long-term effectiveness of a nutritional program in reducing early childhood caries: a randomized trial. Community Dent Oral Epidemiol. 2010;38(4):324-32.

7. Hetherington EM, Parke RD, Locke VO. Child psychology: a contemporary viewpoint. New York: McGraw-Hill; 2003.

8. Piovesan C, Batista A, Ferreira FV, Ardenghi TM. Oral health - related quality of life in children: conceptual issues. Rev Odonto Ciênc. 2009;24:81-5.

9. Pahel B, Rozier RG, Slade G. Parental perceptions of children's oral health: The Early Childhood Oral Health Impact Scale (ECOHIS). Health Qual Life Outcomes. 2007;5(1):6. doi:10.1186/1477-7525-5-6.

10. Li S, Veronneau J, Allison P. Validation of a French language version of the Early Childhood Oral Health Impact Scale (ECOHIS). Health Qual Life Outcomes. 2008;6(1):9. doi:10.1186/1477-7525-6-9.

11. Lee GHM, McGrath C, Yiu CKY, King NM. Translation and validation of a Chinese language version of the Early Childhood Oral Health Impact Scale (ECOHIS). Int J Paediatr Dent. 2009;19(6):399-405.

12. Jabarifar S-E, Golkari A, IJadi M, Jafarzadeh M, Khadem P. Validation of a Farsi version of the Early Childhood Oral Health Impact Scale (F-ECOHIS). BMC Oral Health. 2010;10(1):4. doi:10.1186/1472-6831-10-4.

13. Peker $\mathrm{K}$, Uysal O, Bermek G. Cross - cultural adaptation and preliminary validation of the Turkish version of the Early Childhood Oral Health Impact Scale among 5-6-year-old children. Health Qual Life Outcomes. 2011:9(1):118. doi:10.1186/1477-7525-9-118.

14. Bordoni N, Ciaravino O, Zambrano O, Villena R, Beltran-Aguilar E, Squassi A. Early Childhood Oral Health Impact Scale (ECOHIS). Translation and validation in Spanish language. Acta Odontol Latinoam. 2011;25(3):270-8.

15. Jankauskienè B, Narbutaite J, Kubilius R, Gleiznys A. Adaptation and validation of the early childhood oral health impact scale in Lithuania. Stomatologija. 2012;14(4):108-13.

16. Hadžipašić NA. Translation and validation of the instrument for the oral health-related quality of life assessment in 3 to 5 years old children in Bosnia-Herzegovina. J Health Sci. 2012;2(3):201-6.

17. Scarpelli A, Oliveira B, Tesch F, Leao A, Pordeus I, Paiva S. Psychometric properties of the Brazilian version of the Early Childhood Oral Health Impact Scale (B-ECOHIS). BMC Oral Health. 2011;11(1):19. doi:10.1186/ 1472-6831-11-19.

18. Du R, McGrath C, Yiu CY, King N. Health- and oral health-related quality of life among preschool children with cerebral palsy. Qual Life Res. 2010;19(9):1367-71.

19. Buczynski AKCG, Leão AT, Souza IP. Impact of oral health on the quality of life of 3-6-years old HIV-infected children. quality of life in HIV+ children. Eur J Paediatr Dent. 2011;12(2):81-6.

20. Aldrigui JM, Abanto J, Carvalho TS, Mendes FM, Wanderley MT, Bönecker M, et al. Impact of traumatic dental injuries and malocclusions on quality of life of young children. Health Qual Life Outcomes. 2011;9(9):78. doi:10.1186/1477-7525-9-78.

21. Li MYZQ, Zhou Y, Qiu RM, Lin HC. Impact of early childhood caries on oral health-related quality of life of preschool children. Eur J Paediatr Dent. 2015;16(1):65-72.

22. Klaassen MA, Veerkamp JSJ, Hoogstraten J. Young children's oral health-related quality of life and dental fear after treatment under general anaesthesia: a randomized controlled trial. Eur J Oral Sci. 2009;117(3):273-8.

23. Allen P. Assessment of oral health related quality of life. Health Qual Life Outcomes. 2003;1(1):40. doi:10.1186/1477-7525-1-40.

24. Guedes R, Piovesan C, Antunes J, Mendes F, Ardenghi T. Assessing individual and neighborhood social factors in child oral health-related quality of life: a multilevel analysis. Qual Life Res. 2014;23(9):2521-30.

25. Acquadro C, Conway K, Giroudet C, Mear I. Linguistic validation manual for patient-reported outcomes (PRO) instruments. Lyon: Mapi Research Institute; 2004. 
26. Guillemin F, Bombardier C, Beaton D. Cross-cultural adaptation of health-related quality of life measures: literature review and proposed guidelines. J Clin Epidemiol. 1993;46(12):1417-32.

27. Beaton DE, Bombardier C, Guillemin F, Ferraz MB. Guidelines for the process of cross-cultural adaptation of self-report measures. Spine. 2000;25(24):3186-91.

28. Herdman M, Fox-Rushby J, Badia X. 'Equivalence' and the translation and adaptation of health-related quality of life questionnaires. Qual Life Res. 1997;6(3):237-47.

29. Cronbach $\sqcup$. Coefficient alpha and the internal structure of tests. Psychometrika. 1951;16:297-334.

30. Field A. Discovering statistics using SPSS. 3rd ed. Dubai: Oriental Press; 2009.

31. Bartko JJ. The intraclass correlation coefficient as a measure of reliability. Psychol Rep. 1966;19(1):3-11.

32. Fleiss JL. Statistical methods for rates and proportions. 2nd ed. New York: Wiley; 1981.

33. Inc SPSS. SPSS base 17.0 for windows User's guide. Chicago: SPSS Inc: 2010

34. Kline P. Handbook of psychological testing. 2nd ed. New York: Routledge; 2000.

35. Presser S, Couper MP, Lessler JT, Martin E, Martin J, Rothgeb JM, et al. Methods for testing and evaluating survey questions. Public Opin Q. 2004; 68(1):109-30.

36. Jokovic A, Locker D, Stephens M, Kenny D, Tompson B, Guyatt G. Measuring parental perceptions of child oral health-related quality of life. J Public Health Dent. 2003;63(2):67-72.

37. Clark LA, Watson D. Constructing validity: basic issues in scale development. Psychol Assess. 1995;7(3):309-19.

38. Terwee CBBS, de Boer MR, van der Windt DAWM, Knol DL, Dekker J, Bouter $L M$, et al. Quality criteria were proposed for measurement properties of health status questionnaires. J Clin Epidemiol. 2007;60(1):34-42.

\section{Submit your next manuscript to BioMed Central and we will help you at every step:}

- We accept pre-submission inquiries

- Our selector tool helps you to find the most relevant journal

- We provide round the clock customer support

- Convenient online submission

- Thorough peer review

- Inclusion in PubMed and all major indexing services

- Maximum visibility for your research 